CZU: 634.7

https://doi.org/10.53082/1857-3142.21.86.01

\section{Influența factorilor climatici asupra fenofazelor de dezvoltare a plantelor de mur}

Cristina CATERENCIUC, doctorand,

https://orcid.org/0000-0003-3352-1841;

email: vierul isphta@mail.ru

Institutul Ştiinţifico-Practic de Horticultură şi Tehnologii Alimentare

Rezumat. Lucrarea reprezintă o analiză a cercetărilor stiințifice efectuate în perioada anilor 2018 -2020 la cultura murului, orientată spre studierea adaptabilității soiurilor de mur în condițiile climei schimbătoare. În lucrare sunt prezentate rezultatele cercetărilor și observărilor efectuate asupra parcurgerii fazelor fenologice și durata acestora, care este în corelație directă cu evoluția și intensitatea factorilor ecologici. în urma cercetărilor efectuate privind desfășurarea fenofazelor pe parcursul perioadei de studiu a soiurilor de mur Darrow, Arapaho, Thornfree și Smoothstem, s-a stabilit că: desfacerea mugurilor s-a desfășurat între 27.03 și 20.04, cu durata de 26-58 de zile. Începutul înfloririi a avut loc în perioada 08.05-09.06, cu durata de 15-21 de zile. Maturarea fructelor s-a început în perioada 16.0623.07, cu durata de 33-47 de zile. La soiurile de mur studiate perioada de la începutul vegetației până la maturarea fructelor variază între 86 și 100 de zile.

Cuvinte-cheie: mur, soiuri, fenofaze, factori ecologici.

Abstract. The paper is an analysis of scientific research conducted between 2018-2020 years on blackberry culture, aimed at studying the adaptability of blackberry varieties in changing climate conditions. The paper presents the results of research and observations on the phenological phases and their duration, which is in direct correlation with the evolution and intensity of ecological factors. Following the research carried out on the phenophases during the study period of the blackberry varieties Darrow, Arapaho, Thornfree and Smoothstem, it was established that: the buds took place between 27.03-20.04, with a duration of 26-58 days. The beginning of flowering took place between 08.05-09.06, lasting 15-21 days. The ripening of the fruits started between 16.06-23.07, with a duration of 33-47 days. In the studied blackberry varieties, the period from the beginning of vegetation to fruit ripening varies between $86-100$ days.

Keywords: blackberry, varieties, phenophases, ecological factors.

\section{INTRODUCERE}

Agricultura este un sector extrem de sensibil la condițile climatice. Datele arată că Republica Moldova este expusă la o climă extrem de variabilă, care a cunoscut deja o creștere a temperaturii medii. Astfel, ţara se confruntă frecvent cu diverse fenomene mai puţin prielnice, cum ar fi seceta, creșterea temperaturilor și reducerea precipitațiilor în perioada de vegetaţie a culturilor. lar trecerea de la o climă subumedă la una semiaridă va expune şi mai mult culturile arbustive la noi dăunători și boli [10, p. 2].

Temperatura, de rând cu lumina şi apa, condiţionează desfăşurarea proceselor fundamentale care au loc în plante (fotosinteza, respiraţia, transpiraţia, absorbţia apei etc.). Influenţa temperaturii aerului asupra plantei este strâns legată de acțiunea temperaturii solului. Creşterea şi dezvoltarea plantelor este şi ea dependentă de temperatură, în literatura de specialitate vorbindu-se despre viteza de creştere ca fiind: creşterea raportată la unitatea de timp, iar viteza de dezvoltare se defineşte ca inversul intervalului de timp necesar pentru a trece de la un stadiu de dezvoltare la următorul, adică pentru a parcurge o fază de dezvoltare.

Temperatura influenţează sensibil ritmul de creştere al plantelor, conform legii lui Van't Hoff, după care viteza de creştere se dublează la majorarea temperaturii cu $10^{\circ} \mathrm{C}$, în intervalul $5-35^{\circ} \mathrm{C}$ [8, p.7-8].

Se evidențiază faptul că în cadrul aceleiaşi specii, necesarul de căldură este diferit de la soi la soi. Pentru desfăşurarea diferitor faze fiziologice trebuie să se realizeze o anumită sumă a gradelor de temperatură activă. Pornirea în vegetaţie a speciilor pomicole are loc primăvara numai după atingerea unui anumit prag de temperatură, numit „prag biologic” sau „zero biologic”. Pragul biologic este caracteristic pentru fiecare specie sau grup de specii. De exemplu, pentru arbuştii fructiferi acesta este de $4-5^{\circ} \mathrm{C}$ $[8$, p. 5,10$]$.

Murul este pretențios la temperaturi, atât în perioada de vegetație, cât și în cea de repaus. În timpul iernii, la $-12^{\circ} \mathrm{C}$, o parte din muguri degeră, iar la $15^{\circ} \mathrm{C}$ este afectat și lemnul [5, p. 198].

Dezmuguritul se declanșează după acumularea a 204,2-226 ${ }^{\circ} \mathrm{C}$ de temperaturi active. Pentru deschiderea florilor sunt necesare $630-1050^{\circ} \mathrm{C}$ de temperaturi active, în funcție de soi. Pentru maturarea tuturor fructelor sunt necesare $1700{ }^{\circ} \mathrm{C}$ pentru soiurile timpurii și peste $3000^{\circ} \mathrm{C}$ pentru cele târzii [4, p. 479].

Importanța murului din punct de vedere ecologic: plantele de mur purifică aerul de praf, fum și gaze; asigură o compoziție normală a atmosferei prin consumul de $\mathrm{CO}_{2}$ și eliberează în schimb o cantitate de aproape 3 ori mai mare de oxigen; atenuează extremele de temperatură; măreşte umiditatea relativă a aerului; micșorează viteza vânturilor; favorizează reținerea zăpezii etc. [9, p. 25]. 
Murul cultivat, spre deosebire de cel care crește în flora spontană, este mult mai pretențios față de factorii naturali. Murul cultivat în zonele cu climă de tipul celei continentale crește și fructifică bine numai pe terenurile adăpostite, pe versanții sudici, sud-estici și estici, cu umiditate suficientă. Pe terenurile cu o expoziție însorită, calitatea fructelor este superioară, iar tulpinile se lignifică suficient până la venirea iernii [2, p. 103].

\section{MATERIALE ȘI METODE DE CERCETARE}

Cercetările s-au efectuat pe câmpul experimental al laboratorului „Arbuşti fructiferi și căpșun”. În calitate de obiecte de cercetare au servit soiurile de mur fără ghimpi: Smoothstem, Thornfree, Arapaho şi soiul cu ghimpi Darrow. Anul plantării - 2008. Schema de plantare: $3,0 \times 1,5 \mathrm{~m}$ pentru soiurile de mur de tip rug (Thornfree şi Smoothstem) şi $3 \times 1 \mathrm{~m}$ pentru soiurile de mur cu creştere erectă (Arapaho, Darrow).

Studiul s-a efectuat conform metodelor de câmp şi de laborator prevăzute de programul stabilit pentru arbuştii fructiferi: s-a urmărit fazele de creștere și fructificare la soiurile de mur sub influența factorilor climatici. Astfel, s-au făcut observări asupra desfășurării principalelor fenofaze de dezvoltare a organelor vegetative și de rod. Fenofazele de dezvoltare a organelor vegetative urmărite au fost: dezmuguritul - se marchează data când la majoritatea mugurilor desfăcuţi apar vârfurile frunzuliţelor. Fenofazele de dezvoltare a organelor generative urmărite au fost: înfloritul - marcându-se începutul, când s-au desfăcut 3-5\% de flori, sfârşitul - au înflorit 90-95\% de flori; maturitatea tehnologică a fructelor - odată cu începutul, când se schimbă culoarea fructelor, apar primele fructe colorate; sfârşitul - când fructele s-au copt complet, gustul, aroma și culoarea lor sunt cele caracteristice soiului $[3,6]$.

\section{REZULTATE ȘI DISCUȚII}

Condiţiile meteorologice ale iernii au fost în fond satisfăcătoare pentru soiurile de mur, cel mai călduros a fost sezonul de iarnă 2019-2020. Comparativ cu iarna anului 2018, temperatura medie a aerului în acest sezon a depăşit norma cu $4-5^{\circ} \mathrm{C}$, precipitaţii căzând cu 40-100 mm mai puțin. Cercetările efectuate ne-au permis să acumulăm datele incluse în tabelul 1.

În tabelul 1 este prezentată evoluția principalelor faze fenologice de dezvoltare a plantelor la soiurile de mur studiate, ca moment inițial al declanșării

Fazele fenologice de dezvoltare a soiurilor de mur

Tabelul 1

\begin{tabular}{|c|c|c|c|c|c|c|c|c|c|c|}
\hline \multirow[b]{2}{*}{$\begin{array}{l}\text { Denumirea } \\
\text { soiului }\end{array}$} & \multirow[b]{2}{*}{$\begin{array}{c}\text { Începutul } \\
\text { dezmu- } \\
\text { guririi }\end{array}$} & \multirow[b]{2}{*}{$\begin{array}{c}\text { Durata } \\
\text { dintre } \\
\text { fenofaze }\end{array}$} & \multicolumn{3}{|c|}{ Înfloritul } & \multirow{2}{*}{$\begin{array}{c}\text { Durata } \\
\text { dintre } \\
\text { fenofa- } \\
\text { ze } \\
\end{array}$} & \multicolumn{3}{|c|}{ Maturarea } & \multirow[b]{2}{*}{$\begin{array}{c}\text { Durata } \\
\text { dintre } \\
\text { fenofaze }\end{array}$} \\
\hline & & & $\begin{array}{c}\text { începu- } \\
\text { tul }\end{array}$ & $\begin{array}{l}\text { sfârşi- } \\
\text { tul }\end{array}$ & $\begin{array}{c}\text { durata } \\
\text { perioa- } \\
\text { dei }\end{array}$ & & $\begin{array}{l}\text { înce- } \\
\text { putul }\end{array}$ & $\begin{array}{c}\text { sfârşi- } \\
\text { tul }\end{array}$ & $\begin{array}{c}\text { durata } \\
\text { perioa- } \\
\text { dei }\end{array}$ & \\
\hline Darrow & & & & & & & & & & \\
\hline 2018 & 09.04 & 29 & 08.05 & 23.05 & 15 & 49 & 26.06 & 29.07 & 33 & 82 \\
\hline 2019 & 07.04 & 29 & 06.05 & 22.05 & 16 & 45 & 29.06 & 31.07 & 33 & 78 \\
\hline 2020 & 29.03 & 50 & 19.05 & 05.06 & 17 & 67 & 30.06 & 08.08 & 39 & 106 \\
\hline Media/soi & & 36 & & & 16 & 54 & & & 35 & 87 \\
\hline $\begin{array}{c}\text { Smo- } \\
\text { othstem }\end{array}$ & 17.04 & 38 & 25.05 & 10.06 & 16 & 49 & 12.07 & 15.08 & 33 & 82 \\
\hline 2018 & 20.04 & 39 & 29.05 & 10.06 & 14 & 53 & 15.07 & 19.08 & 34 & 87 \\
\hline $\begin{array}{l}2019 \\
2020\end{array}$ & 08.04 & 57 & 06.06 & 25.06 & 21 & 76 & 20.07 & 29.08 & 40 & 116 \\
\hline Media/soi & & 45 & & & 17 & 60 & & & 36 & 95 \\
\hline Thornfree & & & & & & & & & & \\
\hline 2018 & 20.04 & 38 & 28.05 & 15.06 & 18 & 50 & 16.07 & 20.08 & 34 & 84 \\
\hline 2019 & 18.04 & 37 & 25.05 & 10.06 & 18 & 55 & 19.07 & 22.08 & 33 & 88 \\
\hline 2020 & 10.04 & 58 & 09.06 & 30.06 & 21 & 79 & 23.07 & 08.09 & 47 & 126 \\
\hline Media/soi & & 45 & & & 19 & 62 & & & 38 & 100 \\
\hline Arapaho & & & & & & & & & & \\
\hline 2018 & 13.04 & 28 & 11.05 & $29 . .05$ & 18 & 40 & 20.06 & 23.07 & 33 & 73 \\
\hline 2019 & 31.03 & 30 & 30.04 & 19.05 & 19 & 49 & 22.06 & 25.07 & 33 & 82 \\
\hline 2020 & 27.03 & 49 & 16.05 & 03.06 & 18 & 67 & 16.06 & 21.07 & 35 & 102 \\
\hline Media/soi & & 36 & & & 18 & 52 & & & 34 & 86 \\
\hline Media/specie & & 41 & & & 18 & 57 & & & 37 & 92 \\
\hline
\end{tabular}


acestora, din cursul perioadei de vegetație pe parcursul anilor 2018-2020.

În anul 2020 perioada de vegetație a început mai devreme cu 7-10 zile față de anii precedenți, iar în anii 2018-2019 se observă o diferenţă de 2-4 zile privind termenele desfăşurării fenofazelor de dezmugurire şi înflorire. Cele mai timpurii soiuri de mur sunt Arapaho și Darrow, după care mai târziu pornesc în vegetaţie soiurile Smoothstem şi Thornfree. Dezmugurirea plantelor de mur s-a început în perioada 27.03-20.04, iar până la înflorire a durat în medie 36 de zile la soiurile timpurii și 45 de zile la cele târzii.

În Republica Moldova anul 2020 s-a evidențiat printr-un regim termic înalt şi cantitate anuală de precipitaţii în limitele normei. Temperatura medie anuală a aerului în teritoriu a constituit $+10,7-$ $13,1^{\circ} \mathrm{C}$, depăşind norma cu $2,6-3,7^{\circ} \mathrm{C}$, semnalându-se pentru prima dată pe parcursul întregii perioade de observaţii [7]. Din cauza decalajului de temperaturi, ziua ridicate, iar noaptea scăzute, care a influențat negativ legarea fructelor, înfloritul a avut loc mai târziu comparativ cu anii 2018-2019 (s-a început la data de 16.05-09.06).

Floarea este hermafrodită, corola din 5 petale mari de culoare variată, de la alb la roz. Florile, adunate în inflorescenţe de tip cimă, se deschid eşalonat, pe parcursul a 3 săptămâni, începând din partea superioară a tulpinii spre cea inferioară (fig. 1). Fructul (mura) este format din mai multe drupeole aşezate în jurul receptacolului mic, conic, care la maturitate se desprinde împreună cu fructul (fig. 2) [1, p. 105].
În urma observărilor efectuate, s-a constatat că în funcție de condițiile climatice, stabilite între perioada de înflorire și maturare, coacerea fructelor de mur s-a înregistrat cu o variație de la 56 la 79 de zile de la înflorire. Maturarea fructelor are loc peste 100-128 de zile după umflarea mugurilor, ce corespunde unei acumulări a sumei de temperaturi active de $2000-2200^{\circ} \mathrm{C}$.

Temperatura medie a aerului în anul 2019 a constituit pe teritoriul țării $+10,6-12,6{ }^{\circ} \mathrm{C}$, depăşind norma cu $2,1-3,2^{\circ} \mathrm{C}$, şi pe o mare parte a teritoriului se semnalează pentru prima dată pe parcursul întregii perioade de observații. Comparativ cu anii 2018-2019, în anul 2020 temperatura medie anuală a aerului a fost cu $0,5^{\circ} \mathrm{C}$ mai ridicată şi cantitatea anuală de precipitaţii mai redusă cu 30-80 mm [7].

\section{CONCLUZII}

În urma cercetărilor efectuate la soiurile de mur privind adaptabilitatea la condiţiile climatice ale Republicii Moldova în perioada anilor experimentali cu un regim termic ridicat și deficit de precipitații, s-a constatat:

- în funcție de genotipul soiului de mur, desfăşurarea fenofazelor de dezvoltare a organelor vegetative și de rod are loc diferenţiat, se observă o diferenţă de 9-15 zile privind termenele desfăşurării fenofazelor de dezmugurire şi înflorire între soiurile de mur cu creștere erectă (Arapaho și Darrow) şi soiurile de tip rug (Thornfree, Smoothstem). lar între soiurile de mur Thornfree şi Smoothstem s-a

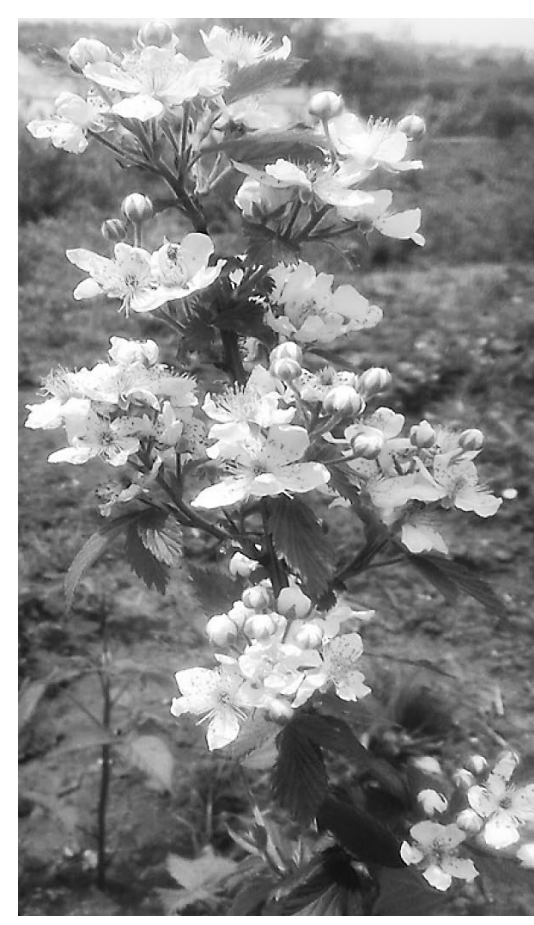

a

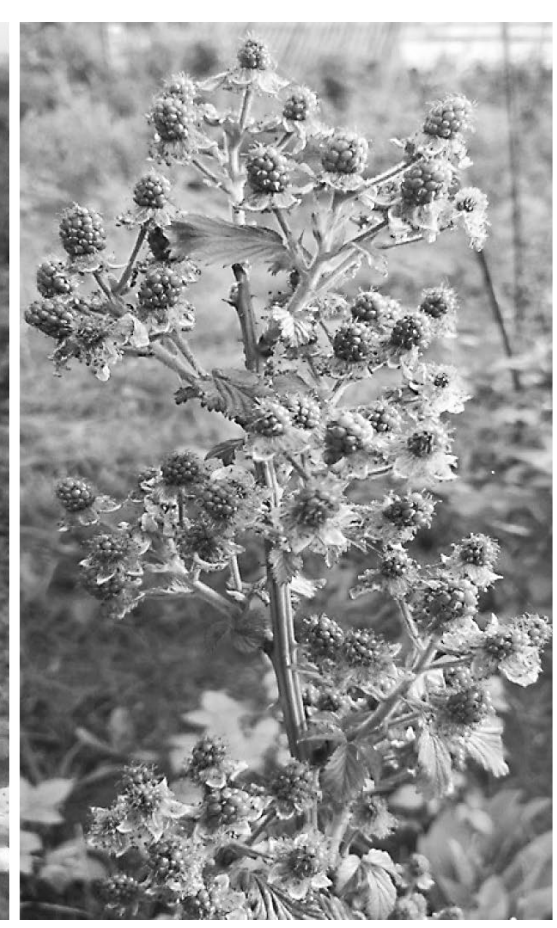

b

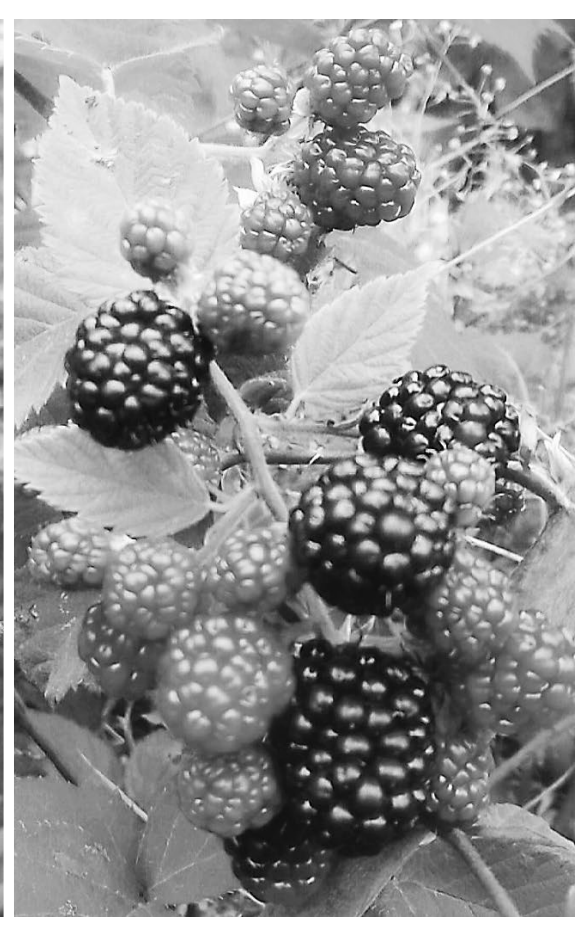

C

Figura 1. Fenofazele plantelor de mur: a) înflorirea; b) legarea fructelor la soiul Darrow; c) maturarea fructelor la soiul Thornfree 
observat o diferenţă de 2-4 zile privind parcurgerea fenofazelor menţionate;

- comparativ cu anii precedenti 2018-2019, pe parcursul anului 2020 la desfășurarea fenofazelor de vegetație s-a înregistrat un decalaj de 7-10 zile mai devreme, datorită prezenței unor valori superioare temperaturii medii, ceea ce demonstrează o ușoară încălzire a climei;

- la soiurile de mur studiate durata dintre fenofazele fenologice de dezmugurire și la maturare a înregistrat o diversitate de la 73 până la 126 de zile, în funcţie de soi și de condiţiile climatice din perioada de vegetaţie.

Notă: Cercetările au fost efectuate în cadrul proiectului „Program de Stat” 20.80009.5107.22A „Elaborarea şi modernizarea tehnologiilor durabile şi ecologice ale speciilor pomicole şi bacifere în condiţiile schimbărilor climatice".

\section{BIBLIOGRAFIE}

1. Balan V., Sava P., Calalb T. Cultura arbuștilor fructiferi și căpșun. Chișinău, Tipogr. Bons Offices, 2017, p. 19-21; 102-110.

2. Chira, Lenuţa. Cultura arbuştilor fructiferi. București, Editura M.A.S.T., 2000, p. 98-108.

3. Cociu V., Oprea Şt. Metode de cercetare în ameliorarea plantelor pomicole. Cluj-Napoca, Editura Dacia, 1989, p. 12-20.

4. Grădinaru G., Istrate M. Pomicultură generală şi specială. Iași, Editura TipoMoldova, 2009, p. 477-483.

5. Mladin Gh., Mladin P. Cultura arbuştilor fructiferi pe spaţii restrânse. București, Editura Ceres, 1992, 198 p.

6. Programa i metodika sortoizucenia plodovîh, iagodnîh $i$ orehoplodnîh kultur. Miciurinsk, VNIIS, 1973, p. 76-90.

7. www.meteo.md

8. http://www.usamvcluj.ro/files/teze/2012/petrisor

9. http://www.cnaa.md/files/theses/2019/54522/mariana lozinschii

10. file:///C:/Users/Kristy/Downloads/2009_romanian_all.pdf

RECENZIE ŞTIINȚIFICĂ - Ilie Donica, doctor habilitat în știinţe agricole, profesor cercetător.

Materialul a fost prezentat la 31.05.2021. 